\title{
Linfadenopatía relacionada con enfermedad por lgG4
}

\author{
Sara Pérez-Moyano1', Alberto Benavente-Fernández², Beatriz Rueda-Villafranca ${ }^{3}$ \\ 'UGC de Medicina Interna, Especialidades Médicas y Cuidados Paliativos. Hospital Comarcal de Baza. Baza (Granada). España \\ ${ }^{2}$ UGC de Medicina Interna. Hospital Universitario San Cecilio. Granada. España \\ ${ }^{3}$ UGC de Anatomía Patológica. Complejo Hospitalario Universitario de Granada. Granada. España
}

Recibido: 08/02/2019

Aceptado: 18/03/2019

En línea: 30/04/2019

Citar como: Pérez-Moyano S, Benavente-Fernández A, Rueda-Villafranca B. Linfadenopatía relacionada con enfermedad por lgG4. Rev Esp Casos Clin Med Intern (RECCMI). 2019 (Abr); 4(1): 27-29. doi: 10.32818/reccmi.a4n1a10.

Autor para correspondencia: Sara Pérez-Moyano. saraperezmoyano84@gmail.com

\section{Palabras clave \\ $\triangleright$ Linfadenopatía \\ $\triangleright$ Inmunoglobulina lgG4 \\ $\triangleright$ Enfermedad relacionada con lgG4}

\begin{abstract}
Resumen
Hombre de 49 años que acudió a consulta de Medicina Interna por febrícula y adenopatías axilares dolorosas de 7 meses de evolución sin otra sintomatología asociada. No antecedentes personales de interés ni hábitos tóxicos. Analíticamente sin datos patológicos. En distintas pruebas de imagen (ecografía, tomografía axial computarizada de tórax-abdomen-pélvis), se confirmó la presencia de múltiples adenopatías de tamaño no despreciable axilares e inguinales, por lo que se derivó a Cirugía para extirpación de las mismas. El resultado de la anatomía patológica indicó células plasmáticas de predominio lgG4, presentándose cociente $\operatorname{lgG} / \operatorname{lgG}>0,4$. El resultado analítico fue normal, a excepción de una elevación leve de lgG4. Se inició tratamiento corticoideo, desapareciendo las mismas.

Abstract
We present the case of a 49 year old man without previous diseases but toxic habits, who consulted to our Inter-
nal Medicine Outpatient department due to the presence of mild fever and painfull axillar lymphadenopathies
lasting for 7 months, with no other accompanying symptoms. Image tests (echography and body-scan) con-
firmed the presence of multiple pathologic size axillary and inguinal lymphadenopathies, being transferred to
surgery to proceed with lymphadenectomy. Anatomopathological lymphadenopathy study showed plasmatic
cells with predominance of IgG4, with a IgG4/IgG ratio > 0.4. Analytic study was unremarkable, except for a mild
IgG4 elevated value. Corticosteroid therapy is started, achieving complete resolution.
\end{abstract}

\section{Puntos destacados}

$\triangleright$ Las enfermedades relacionadas con IgG4, son un grupo de enfermedades relativamente desconocidas por haberse reconocido en su descripción y nomenclatura en los últimos 15 años, por su gran heterogeneidad e inespecificidad, así como por el hecho de su baja frecuencia; tal es así, que se considera un grupo de enfermedades raras (ORPHA284264)'

$\triangleright$ El caso aportado quiere reforzar el conocimiento sobre esta enfermedad o grupo de enfermedades, destacando la necesidad de realizar un diagnóstico diferencial adecuado y un tratamiento precoz.

\section{Introducción}

La enfermedad relacionada con lgG4 (ER-lgG4) incluye diversas enfermedades caracterizadas por infiltración linfoplasmocítica, presencia de un número elevado de células IgG4, fibrosis y, en un número elevado de casos, niveles elevados de lgG4 en suero. Afecta principalmente a páncreas, glándulas salivares, ganglios linfáticos, árbol biliar, tejidos periorbitales, riñones, pulmones y retroperitoneo, pudiendo verse dañada casi cualquier estructura del organismo

El primer caso clínico compatible con esta enfermedad data de 1892 y fue diagnosticado por el Dr. Mikulicz al realizar la autopsia de un paciente que presentaba "edema simétrico de glándulas lacrimales, parotídeas y submandibulares con infiltración masiva de células mononucleares". Se objetivaron en dicha autopsia datos muy semejantes a los presentados en los linfomas MALT, por lo que obliga al clínico a descartar malignidad.

Su etiología no está clara actualmente, aunque una de las últimas teorías propone que esta enfermedad es secundaria a la interacción entre células Th2 y células B que resulta en concentraciones elevadas de lgG4 y mediadores inflamatorios, eventos que se expresan a nivel tisular como infiltrados linfoplas- 
mocitarios y fibrosis, no siendo éste el único mecanismo que parece favorecer el desarrollo de la enfermedad.

\section{Historia clínica}

Varón de 49 años, fumador de tabaco y marihuana, consumidor de alcohol. No otros antecedentes personales y, entre los familiares, padre fallecido por un linfoma. Fue derivado a consulta de Medicina Interna por tumoración axilar derecha dolorosa y febrícula vespertina intermitente de 7 meses de evolución.

En la exploración física destacaba IMC $34,6 \mathrm{~kg} / \mathrm{m}^{2}$ (obesidad clase I) con buen estado general. Se palpaban adenopatías a nivel axilar derecho de consistencia gomosa, no adheridas a plano profundos, dolorosas a la palpación, de aproximadamente $3 \mathrm{~cm}$ de diámetro; y adenopatías de parecidas características pero de menor tamaño a nivel en ambas cadenas ganglionares inguinales y en axila izquierda.

El estudio ecográfico axilar objetivó "al menos tres imágenes hipoecogénicas, de contorno lobulado, alargadas a nivel de tejido celular subcutáneo axilar inferior derecho. La más craneal y de mayor tamaño de aproximadamente $4 \mathrm{~cm}$ de longitud con un grosor cortical de $1,8 \mathrm{~cm}$ sin aumento de la vascularización". Se completó el estudio con tomografía axial computarizada (TAC) de tóraxabdomen-pelvis que confirmó la "presencia de ganglios inguinales bilaterales de hasta 10-12 mm. Adenopatías axilares derechas midiendo mayores de $15 \mathrm{~mm}$. En axila izquierda se observan otras imágenes ganglionares de entre 8-15 mm. Resto sin hallazgos".

Se derivó al paciente a Cirugía para extirpación de adenopatía axilar, siendo el resultado de la anatomía patológica: "ganglio linfático con arquitectura conservada en el que se observa fibrosis de la zona perihiliar así como hiperplasia de folículos linfoides que se distribuyen tanto por la cortical como por la medular y cuyos centros presentan un fenotipo normal, con algunas células plasmáticas intrafoliculares. Las células plasmáticas que se observan son mayoritariamente lgG y mayoritariamente lgG4. El cociente lgG4/lgG es mayor de 0,4" (Figura 1, Figura 2 y Figura 3).

El estudio analítico de sangre incluyó perfil hepático general (renal, hepático, tiroideo, iónico), estudio de autoinmunidad/inflamatorio (ANA, ENA, ANCA, FR y EC, FR y ECA), infeccioso (citomegalovirus, virus de Epstein-Barr, toxoplasma, virus de la inmunodeficiencia humana...) y de procesos hematológicos (proteinograma, complemento C3-C4, $\beta_{2}$-microglobulina, así como proteínas y cadenas en orina de 24 h); y resultó compatible con la normalidad, a excepción de la elevación sérica de los niveles de la subunidad lgG4: 120 mg/dl (3,92-86,4 mg/dl). Se solicitó PET-TAC, apreciándose foco hipermetabólico en retroperitoneo para cavo con SUV 5,10 compatible con proceso neoplásico vs inflamatorio.

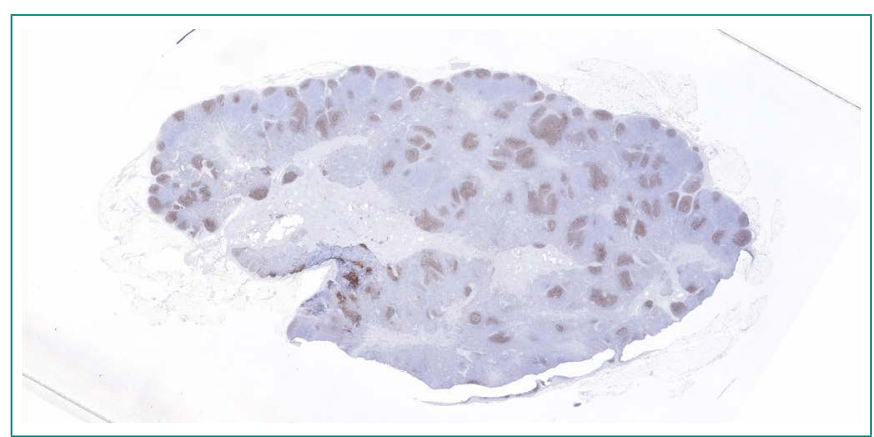

Figura 1. Estructura ganglionar que muestra una hiperplasia folicular puesta de manifiesto mediante CD21

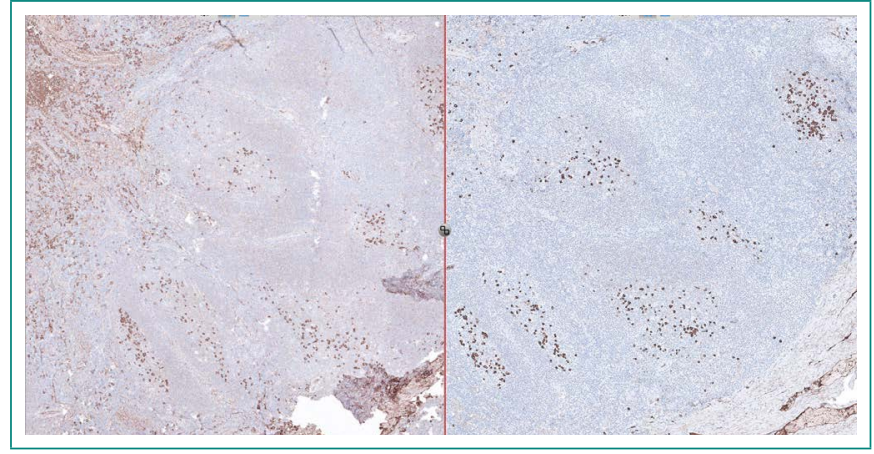

Figura 2. A mayor aumento se objetivan células plasmáticas intrafoliculares

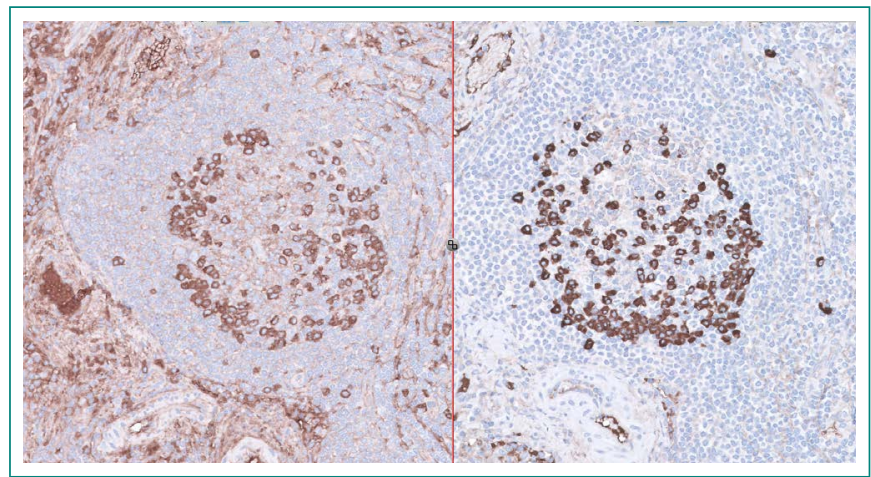

Figura 3. Células plasmáticas intrafoliculares lgG expresan a su vez lgG4

\section{Evolución}

Tras el resultado del PET-TAC se comentó el caso en sesión clínica junto con Cirugía y Radiología, decidiéndose, dada la ausencia de clínica del paciente y el difícil acceso para la extirpación de la adenopatía objetivada, seguimiento clínico. Debido a la presencia de criterios diagnósticos de probable linfadenopatía relacionada con enfermedad por lgG4, y pudiendo reforzar el diagnóstico, se inició tratamiento con prednisona, iniciándose a dosis de 40 mg/día, realizándose un descenso de $5 \mathrm{mg}$ semanal hasta suspender. Se solicitó nuevo PET-TAC en 3 meses, que confirmó la desaparición del foco metabólico (Figura 4).
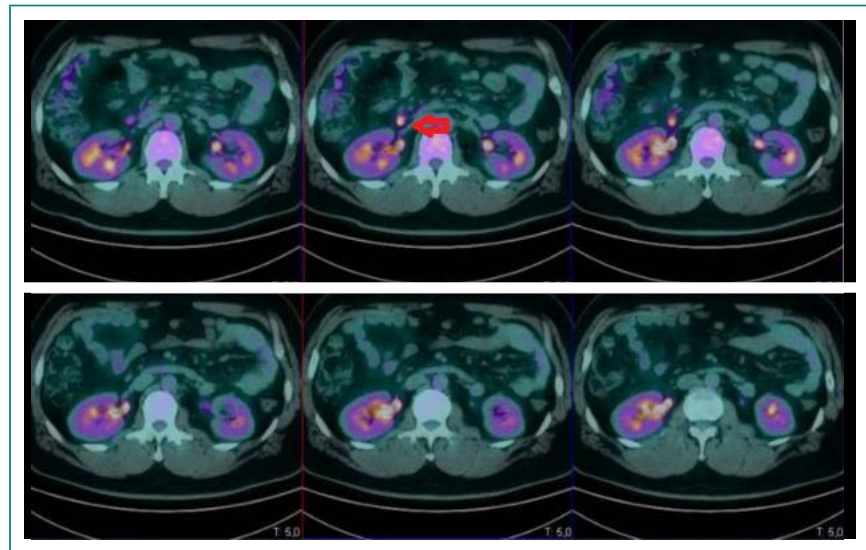

Figura 4. PET-TAC. Foco hipermetabólico para cavo en las tres imágenes superiores correspondientes al primer estudio. En el segundo estudio, al que corresponden las imágenes inferiores, dicho foco ha desaparecido 


\section{Juicio clínico}

Probable linfadenopatía relacionada con enfermedad por lgG4.

\section{Discusión y conclusiones}

La ER-IgG4 es una enfermedad autoinmunitaria sistémica, con posible afectación a nivel de múltiples órganos y sistemas, recientemente descrita y de etiología no clara. Por tanto, los internistas deberían tener un papel destacado en el diagnóstico, tratamiento y seguimiento de estos pacientes. Se caracteriza por infiltrado linfoplasmocitario que expresa lgG4 en los distintos órganos afectados y aumento de lgG4 en sangre en algunos casos. Las manifestaciones clínicas pueden ser muy diversas, dependiendo del órgano afecto, habiéndose descrito patología relacionada por lgG4 de forma predominante sobre páncreas, sistema hepatobiliar, tiroides, glándulas salivares y lacrimales, órbitas, retroperitoneo, mediastino, sistema pleuropulmonar, arterias, riñones y ganglios linfáticos ${ }^{3}$. Se ha observado predominancia en hombres (8:1) y en edades superiores a 50 años ${ }^{4}$.

Su diagnóstico constituye un reto para el clínico y se basa principalmente en los resultados histopatológicos de la biopsia y en la inmunohistoquímica: infiltrados linfoplamocitarios densos, fibrosis dispuesta al menos focalmente en un patrón estoriforme, flebitis obliterativa, incremento del número de eosinófilos 5 . Aunque la lgG4 es la responsable del nombre de la enfermedad, no se encuentra elevada en la totalidad de los pacientes o su aumento es mínimo, siendo nuestro caso un ejemplo de ello. Si bien no existen criterios internacionalmente aceptados para el diagnóstico, los de mayor utilidad actualmente son los criterios de Okazaki (Tabla 1$)^{2}$.

\section{ER-IgG4 (criterios de Okazazi et al.)}

1. Agrandamiento o lesiones focales o difusas en uno o más órganos

2. Concentraciones séricas de lgG4 > $135 \mathrm{mg} / \mathrm{dl}$

3. Histopatología:

a. Infiltrado linfocitario y plasmocítico con fibrosis, sin infiltrado neutrofílico

b. Infiltrado de plasmocitos IgG4 positivos > 10/cap

o proporción de células lgG4/lgG > 40\%

c. Fibrosis estoriforme-remolino

d. Flebitis obliterativa

El diagnóstico definitivo se realiza con el cumplimiento de alguna

de las siguientes combinaciones:

- $1+2$

- $1+3(a+b)$

- $2+3(a+b)$

- $3(a+b+c+d)$

Tabla 1. Criterios diagnósticos de Okazazi et al.

Para el diagnóstico de nuestro caso, y dado que posiblemente sea la suma de los criterios clínicos, histológicos y serológicos los que definan la ausencia o presencia de enfermedad, nos basamos en los criterios adaptados de Ryu et al. (Tabla 2)². Según los mismos, y dado que la lgG4 sérica no es superior a $135 \mathrm{mg} / \mathrm{dl}$, se trataría de una enfermedad probable por lgG4 ${ }^{6}$.

\begin{tabular}{|c|c|c|c|}
\hline Clínica & Serología & Histopatología & $\begin{array}{c}\text { Calidad } \\
\text { diagnóstico }\end{array}$ \\
\hline $\begin{array}{l}\text { Compromiso de órgano: } \\
\text { disfunción, edema } \\
\text { localizado o difuso }\end{array}$ & $\begin{array}{l}\text { lgG4 sérica } \\
>135 \mathrm{mg} / \mathrm{dl}\end{array}$ & $\operatorname{lgG} 4 / \operatorname{lgG}>0,4$ & Definitivo \\
\hline $\begin{array}{l}\text { Criterios específicos } \\
\text { de órgano para lgG4 }\end{array}$ & $\begin{array}{l}\text { Criterios } \\
\text { específicos } \\
\text { de órgano } \\
\text { para lgG4 }\end{array}$ & $\begin{array}{l}\text { Criterios } \\
\text { específicos } \\
\text { de órgano } \\
\text { para lgG4 }\end{array}$ & Definitivo \\
\hline $\begin{array}{l}\text { Compromiso de órgano: } \\
\text { disfunción, edema } \\
\text { localizado o difuso }\end{array}$ & $\begin{array}{l}\text { lgG4 sérica } \\
<135 \mathrm{mg} / \mathrm{dl}\end{array}$ & $\operatorname{lgG} 4>0,4$ & Probable \\
\hline $\begin{array}{l}\text { Compromiso de órgano: } \\
\text { disfunción, edema } \\
\text { localizado o difuso }\end{array}$ & $\begin{array}{l}\text { lgG4 sérica } \\
>135 \mathrm{mg} / \mathrm{dl}\end{array}$ & $\begin{array}{l}\text { No disponible } \\
\text { o no } \\
\text { diagnóstica }\end{array}$ & Probable \\
\hline $\begin{array}{l}\text { Compromiso de órgano: } \\
\text { disfunción, edema } \\
\text { localizado o difuso }\end{array}$ & $\begin{array}{l}\text { lgG4 sérica } \\
<135 \mathrm{mg} / \mathrm{dl}\end{array}$ & $\begin{array}{l}\text { No disponible } \\
\text { o no } \\
\text { diagnóstica }\end{array}$ & No considerar \\
\hline
\end{tabular}

Tabla 2. Certeza del diagnóstico de ER-IgG4 según criterios diagnósticos (adaptada de Ryu et al.)

El clínico debe decidir si el paciente requiere tratamiento, siendo en la mayor parte de las ocasiones esta respuesta afirmativa. Las razones a favor del inicio del mismo suelen ser la mejor respuesta y pronóstico con el inicio de un tratamiento temprano del órgano afecto, la respuesta beneficiosa del mismo y la posibilidad de limitar la afectación a otros órganos. En el caso presentado, se decidió seguimiento estrecho en consulta e inicio de tratamiento con prednisona $40 \mathrm{mg} / \mathrm{dí}^{2}$ (dosis $<0,5 \mathrm{mg} / \mathrm{kg}$ ) reduciendo semanalmente $5 \mathrm{mg}$ hasta suspender, tras no poder descartar lesión maligna en el primer PET-TAC realizado, siendo la respuesta al tratamiento muy favorable, lo cual apoya de forma evidente el diagnóstico de ER-lgG4. No existe evidencia del uso con ahorradores de corticoides pero sí se han publicado datos sobre el uso de rituximab como terapia de inducción y mantenimiento con buena y sostenida respuesta clínica, por lo que se plantea como terapia de segunda línea².

\section{Bibliografía}

1. Ardila-Suárez O, Abril A, Gómez-Puerta JA. IgG4-related disease: a concise review of the current literature. Reumatol Clin. 2017 May-Jun; 13(3): 160166. doi: 10.1016/j.reuma.2016.05.009.

2. Carrillo-Esper R, Echervarría Vargas JA. Enfermedad relacionada con IgG4. Med Int Mex. 2013; 29(1): 53-61.

3. Erlij D, Ramos D, Montaña J, Kusnir P, Correa G, Neira O. IgG4-related disease, the new "great mimicker": report of one case. Rev Med Chil. 2014 May; 142(5): 646-650. doi: 10.4067/S0034-98872014000500014.

4. Wick MR, O'Malley DP. Lymphadenopathy associated with IgG4-related disease: diagnosis \& differential diagnosis. Semin Diagn Pathol. 2018 Jan; 35(1): 61-66. doi: 10.1053/j.semdp.2017.11.006.

5. Deshpande V, Zen Y, Chan JK, Yi EE, Sato Y, Yoshino T, et al. Consensus statement on the pathology of IgG4-related disease. Mod Pathol. 2012 Sep; 25(9): 1181-1192. doi: 10.1038/modpathol.2012.72.

6. Pieringer H, Parzer I, Wöhrer A, Reis P, Oppl B, Zwerina J. IgG4-related disease: an orphan disease with many faces. Orphanet J Rare Dis. 2014 Jul 16; 9: 110. doi: 10.1186/s13023-014-0110-z. 